IRA-International Journal of Applied Sciences ISSN 2455-4499; Vol.11, Issue 02 (May 2018)

Pg. no. 9-29.

Institute of Research Advances

https://research-advances.org/index.php/IRAJAS

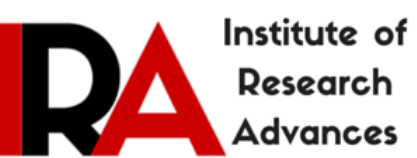

\title{
Vortex Valve - Principle, Design and Application
}

\author{
Karel Adámek ${ }^{1 \#, ~ J a n ~ K o l a ́ ~} \check{r}^{2}$, and Pavel Peukert ${ }^{3}$ \\ 1,2,3 VÚTS Liberec, a.s., Department of Flow Simulations, Svárovská 619, 46119 Liberec, Czech Republic.
}

\#corresponding author.

Type of Review: Peer Reviewed.

DOI: http://dx.doi.org/10.21013/jas.v11.n2.p1

How to cite this paper:
Adámek, K., Koláŕ, J., Peukert, P. (2018). Vortex Valve - Principle, Design and Application. IRA International Journal of Applied Sciences (ISSN 2455-4499), 11(2), 9-29. doi:http://dx.doi.org/10.21013/jas.v11.n2.p1

(c) Institute of Research Advances.

(cc) EY-NC

This work is licensed under a Creative Commons Attribution-Non Commercial 4.0 International License subject to proper citation to the publication source of the work.

Disclaimer: The scholarly papers as reviewed and published by the Institute of Research Advances (IRA) are the views and opinions of their respective authors and are not the views or opinions of the IRA. The IRA disclaims of any harm or loss caused due to the published content to any party.

Institute of Research Advances is an institutional publisher member of Publishers International Linking Association Inc. (PILA-CrossRef), USA. The institute is an institutional signatory to the Budapest Open Access Initiative, Hungary advocating the open access of scientific and scholarly knowledge. The Institute is a registered content provider under Open Access Initiative Protocol for Metadata Harvesting (OAI-PMH).

The journal is indexed \& included in CAS Source Index of Chemical Abstracts Service of American Chemical Society (USA), Index Copernicus (IC Value 85.27), WorldCat Discovery Service (USA), CrossRef Metadata Search (USA), WorldCat (USA), OCLC (USA), Open J-Gate (India), EZB (Germany) Scilit (Switzerland), Airiti (China), Bielefeld Academic Search Engine (BASE) of Bielefeld University, Germany, PKP Index of Simon Fraser University, Canada. 


\begin{abstract}
The paper contains the overview of so-called vortex valve, used as outlet device on retention reservoirs for retention of rainstorms and later slow outflow into drainage etc. Simple onedimensional equations are well known, but for complex three-dimensional flow fields inside the valve the method of flow numerical simulation is used. Particular paragraphs contain the theory of flow fields inside, explanation of branched flow characteristic, separated by transitional area, basics of designing and influence of both inlet/outlet opening sizes on the form of characteristic, valve adaptation for high flows at low water levels etc. Results are used for designing of new model series of valves for various water flows and levels.
\end{abstract}

Keywords: Vortex valve, flow numerical simulation, flow-pressure characteristic, two phases-flow

\title{
1 INTRODUCTION
}

There is many types of devices, used for different purposes, called vortex valves. Here is described the vortex valve, mounted usually on the outlet from retention reservoir. Such reservoir is used for instance as the retention of the rainstorm or similarly and for the consecutive slow outflow into drainage etc. The principle of operation is described curiously by Mr. Google and many dealers and producers, for instance as "the effect is given by flow phenomenon" or "it works on the principle of hydraulic phenomenon". Reality is not so mysterious, the flow inside of such valve is possible to describe by several essential equations of fluid mechanics. For complex three-dimensional flows is better to use numerical flow simulation. However, about vortex valves exist serious works, too, as for instance [1-5] etc.

This article summarizes former partial results. The first part deals with creation of unusual branched characteristic pressure-flow of the valve and of basics of designing main valve dimensions for given water level and water flow [6]. The second part deals with valve adaptation for lower water levels together with higher water flows [7].

\section{MODEL OF LOWER FLOWS}

The aim of the first part of the study about so-called vortex valve is the statement of the resistanceflow characteristic

$$
\Delta p[P a]=f\left(V\left[m^{3} / s\right]\right)
$$

moreover, the reason of its branching. The influence of main design parameters, first of all inlet/outlet diameters, is discussed, too. Generally, the design depends on given water flow $\left(\mathrm{m}^{3} / \mathrm{s}\right)$ and water level before the valve, presented as hydrostatic pressure $(\mathrm{Pa})$.

For following flow, numerical simulations there is used standard commercial software [8].

\subsection{Geometry}

The valve shape in the original patent [9] is quite complicated in comparison with actual design below. Used model [6] contains six liquid bodies, see the Fig. 1, without surrounding retention reservoir - it assumes that the velocity range in such surrounding can be neglected in comparison with flow inside the studied valve. Such simplified model without entry part allows shortening the time of solution.

1.Inlet - cylindrical tangential, situated from below.

2.Chamber - cylindrical with horizontal axis, tangential inlet and axial outlet.

3.Outlet - horizontal axial hollow on the forefront.

4. Outlet flange - outlet prolongation.

5.Vent opening - small orifice in the highest point of the chamber.

6. Outer surroundings (air) - is minimalized here, smaller volume of the model means shorter time of the solution. 
In this model the flow resistance $\Delta p[P a]=f\left(V\left[\mathrm{~m}^{3} / s\right]\right)$ of the valve is solved, only, the shape of the outer flow (or its spraying quality) is not important here, it is not the aim of this work.

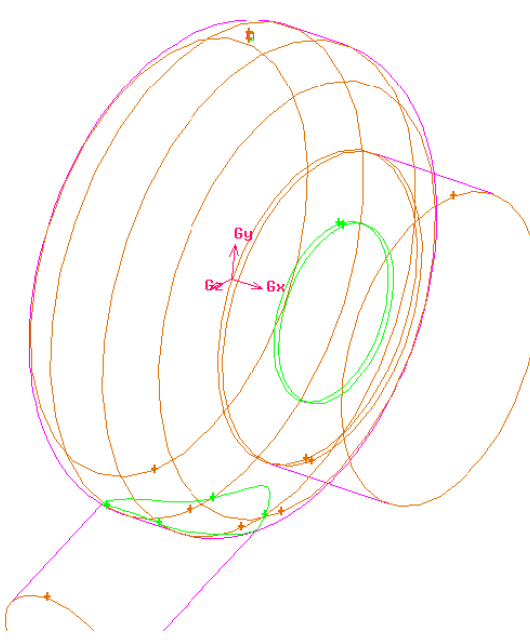

geometry

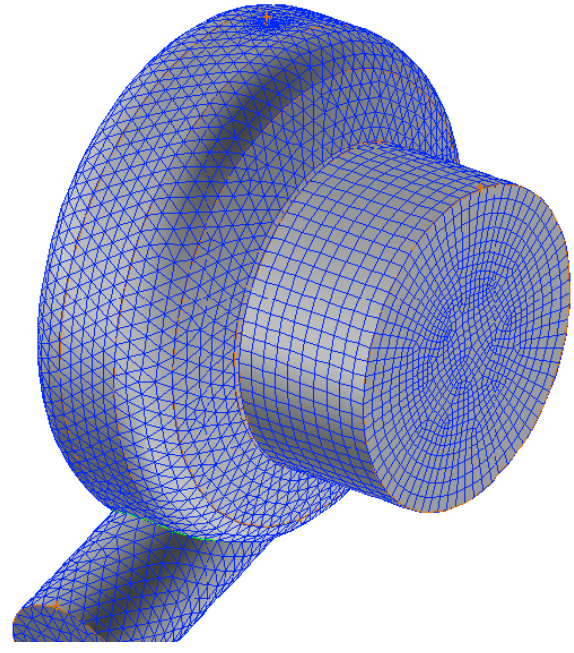

mesh

Fig. 1: Model creation

Regarding the complicated two-phase flow, it is necessary to use fine calculating mesh after the Fig. 1 , first near the outlet, where the flow is disintegrating and mixing. The initial mesh modifies yet during calculation.

\subsection{Boundary and initial conditions}

In the inlet cross-section there is simply defined constant (hydrostatic) pressure, given by the height of surrounding (inlet) water level. Zero pressure is defined here in the middle of this inlet cross-section. Really, the pressure distribution in the inlet is not constant, differences are neglected hereafter.

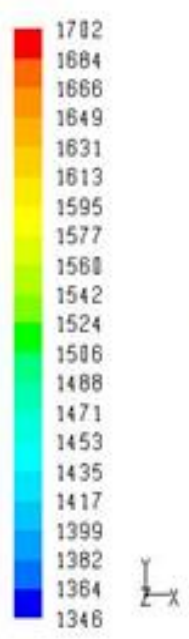

(water level of $0.16 \mathrm{~m}$ )

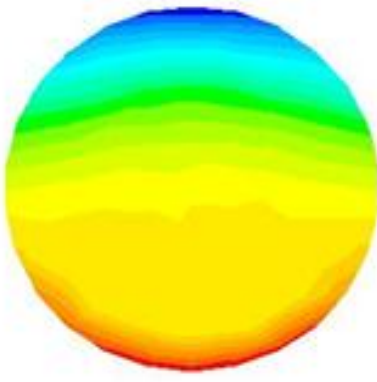

Fig. 2: Uneven inlet pressure field
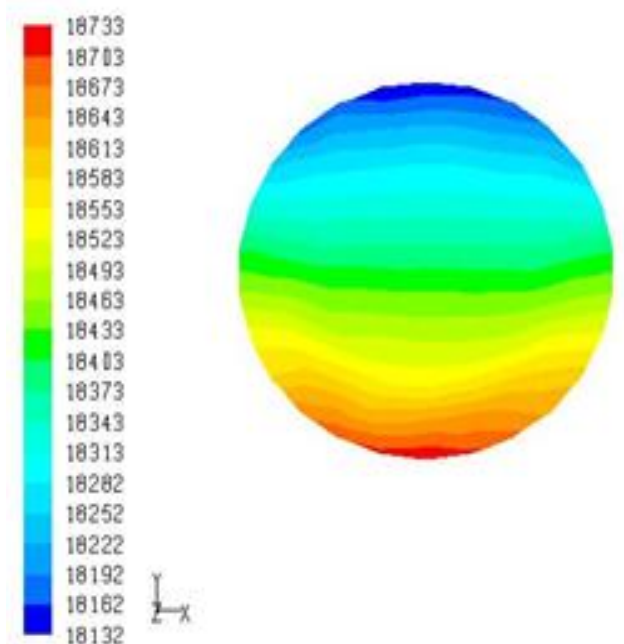

(water level of $2.0 \mathrm{~m}$ ).

The Fig. 2 presents real pressure fields in the inlet cross-section for min. and max. water levels of 0.16 $\mathrm{m}$ and $2.0 \mathrm{~m}$ - some part of defined static pressure changed yet for kinetic energy of the flow. Corresponding pressure differences for min. /max. water levels are 350/600 Pa, only - neglected. In the surroundings, there is zero pressure (atmosphere).

Operational condition - gravity acceleration of $9.81 \mathrm{~m} / \mathrm{s}^{2}$ in the down direction - axis (-y). 
Initial conditions:

Inlet - the mixture pressure max. $20 \mathrm{kPa}$, the value of the phase $\mathrm{f} 2$ is equal to zero (water only), Outlet - the mixture pressure $0 \mathrm{~Pa}$, with defined backflow of the phase 2 equal to 1 (air only).

\subsection{Solver}

Isothermal model (if speculating about friction losses, the water warming would be of some $0.01 \mathrm{~K}$, only). Turbulence model k- $\omega$ SST.

Two models of two-phase (water-air) flow were tested: unsteady model „VOF“ (volume of fluid) with very short time step and steady model ,mixture“.

\subsubsection{Unsteady model VOF (volume of fluid)}

As an illustration, only, the testing images of both phases after several first time steps of the solution are presented on the Fig. 3 for low and high inlet pressure. The simulation is not finished, informative phases fields are captured shortly after the start of long-term solution. The short time step of $0.1 \mathrm{~ms}$ approx. was necessary, to get converged solution. Nevertheless, the time of solution is very long.

The field of both phases is very detailed, captured in the actual time step of the unsteady solution. Using low pressure, the water (blue, phase $\mathrm{f} 2=0$ ) is flowing mainly down, owing to gravitation inside there is not any important rotating flow yet. In the surrounding there is air (red, phase $\mathrm{f} 2=1$ ). Using higher pressure, the axial flow becomes more dominant.

The here used large surroundings volume (right side) was deleted later, to shorten the solution time.

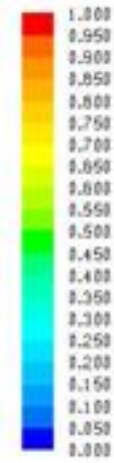

low pressure difference, $0.7 \mathrm{~s}$ after start

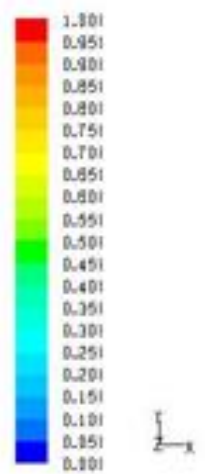

high pressure difference, $0.35 \mathrm{~s}$ after start

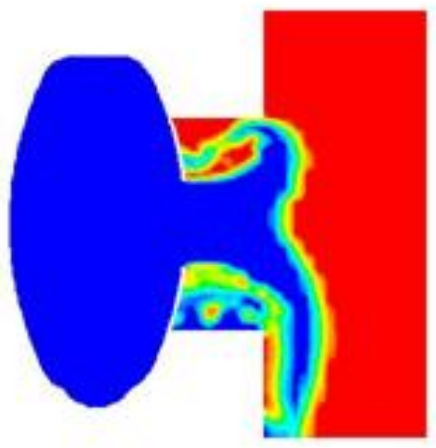

Fig. 3: Phase interface (water/air) for different pressure differences and models

\subsubsection{Steady model "mixture”}

After the verification of the proper progress of the solution, results of this model are used below. From the results follows that the interface water-air is changing in the time, so that the presented result is any fictive steady flow field, captured in any actual time of the solution. This unsteady timedependent water level (surface) gives the relatively large boundary water-air, see below in the Par. 3 .

Comparison of both methods: The values of the flow, received by unsteady method with the time step of $10 \mathrm{~ms}$, are of 6-7\% smaller in comparison with steady method ,mixture" and with the time step of $0.1 \mathrm{~ms}$ of $3 \%$ smaller. Probably, it is some numerical mistake between both used models - without next investigation.

However, in this study is not necessary to solve details of the flow field, the solution is regarded as converged, when the difference between inlet and outlet flow is less than $0.1 \mathrm{~kg} / \mathrm{s}$, i.e. $1 \%$ approx. of the nominal flow. 


\subsection{Principles of vortex valve operation}

Generally, the device of mentioned type contains two critical necks. If the flow control is realized by the change of outlet cross section, which is well accessible during the operation, then both the inlet cross section and inner volume must be large enough, to be able to work as a large pressure vessel. Then the water is flowing out through small orifice as from a nozzle, the outflow is strong of high dynamic effect on the surroundings. As soon as the outlet is larger, the control function is taking over by the inlet cross section, which defines the flow. In the increased outlet then is flowing the same volume, as allowed by the inlet. After the continuity equation in the larger cross section is lower flow velocity.

Idealized inlet velocity wid is given by inlet water level $H$ as

$$
\text { wid }=\sqrt{ }(2 . g . H)
$$

real value wo is lower due to many flow resistances inside, represented by the flow coefficient $\varphi$

$$
w o=\varphi \text {. wid. }
$$

The water flow rotates inside due to the tangential inlet into the valve body. To reach a reliable rotation in the vortex valve with horizontal axis of rotation, the centrifugal acceleration $a o$ in valve body of radius $r o$ must be reliably higher than the gravity $g$

$$
a o=w o^{2} / r o>g \text {. }
$$

Generally, for the given flow the peripheral velocity is higher at lower radius, it means that the centrifugal acceleration is higher, too.

Cases of very complicated three-dimensional flow field inside the vortex valve must be solved by flow numerical simulation. The exact relation of $a o / g$ is not possible to determine simply from the simulated flow field, because the values of $w o$ and $r o$ is not possible to read exactly from images of velocity (see for instance the Fig. 4 below). After the simplified hypothesis, the circular inlet cross section passes into annular body of the same cross section, rotating along the periphery of valve body. The radius of the rotating flow, as the operational point of the centrifugal acceleration could be preliminary estimated as the distance of the cross section center of such rotating mass body from the axis of the rotation.

Due to the influence of centrifugal forces, the outflowing and rotating water flow is concentrated along the periphery of valve body and into the middle (axial) volume there is observable the air suction inside from outlet surroundings. The outgoing water is separating on the outlet edge and creates more or less sprayed mixture of water and air. The dynamic effect of such flow on ambient walls is not as strong as a compact axial water stream. Its energy is partially lost by complicated flow inside the valve body and the average density of the outgoing mixture of water and air is lower as the compact water flow.

The Fig. 4 of the cross section in the velocity field was used for approximate assessment of the peripheral velocity $w o$ and of the average radius $r o$ of rotating annular water body for the calculation of centrifugal acceleration $a o=w o^{2} / r o$. It is very rough assessment, only, but generally said, that for reliable spraying the centrifugal acceleration must be higher enough than the gravity. It is visible that it is difficult to state an exact average velocity of the fluid body, rotating along the valve outlines and its average radius, too.

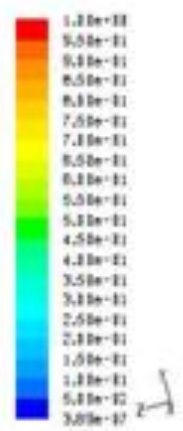

a) not converged, shortly after simulation start
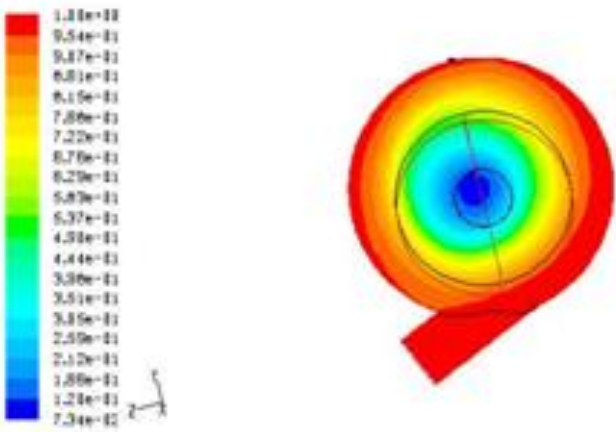

b) converged, steady state

Fig. 4: Velocity fields in the cross section 
The Fig. 5 presents the influence of gravitation, affecting in perpendicular direction to the outlet axis, on the spray quality. The valve body is vaulted, using standardized semi-finished product [9-12], used for smaller water flows.

a) Idealized large flow modelled without gravitation - inner flow rotation together with the centrifugal acceleration create at the outlet clearly visible symmetric spraying of water (ao $=15$ $\mathrm{m} / \mathrm{s}^{2}$, ao/g $\left.=1.5\right)$.

b) Real large model with gravity - the centrifugal acceleration is not too high $\left(\mathrm{ao}=11 \mathrm{~m} / \mathrm{s}^{2}, \mathrm{ao} / \mathrm{g}=\right.$ 1.1), the flow is due to the gravity partially bent down and partially is closing the outlet.

c) Check smaller model with gravity. The centrifugal acceleration in the smaller valve body diameter is quite high ( $\mathrm{ao}=21 \mathrm{~m} / \mathrm{s}^{2}, \mathrm{ao} / \mathrm{g}=2.1$ ), good water spraying in the outlet, due to the gravity is slightly different up and down.

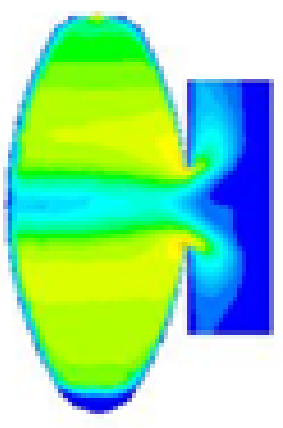

a) no gravity, well sprayed

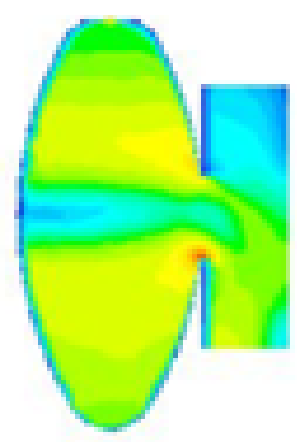

b) with gravity, low pressure, not sprayed

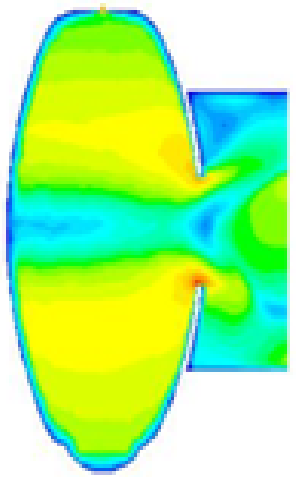

c) with gravity, high pressure, well sprayed

Fig. 5: Velocity field at different influence of centrifugal acceleration

\section{INFLUENCE OF OPERATIONAL PARAMETERS}

As mentioned above in the Par. 2.3.2, the steady model of two-phases flow „mixture“ is used, the steady shape of the water level is displayed below for solved cases.

The thick interface water/air represent the real level waviness, therefore the time-averaged positions of the water level are displayed. The tangential bottom inlet creates rotational flow, but at partially filled chamber, the water level is very chaotic, uneven. This action is unsteady and used steady model „mixture“ records any average steady state in any actual time.

\subsection{Flow fields for various water levels}

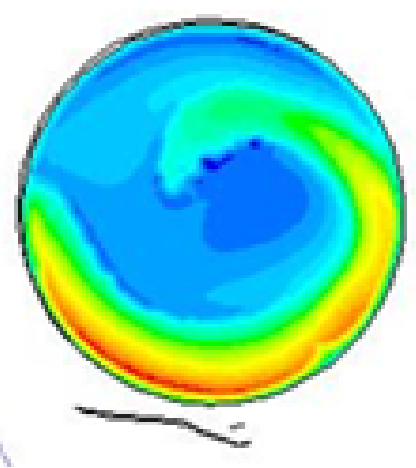

ao low - flow is falling over

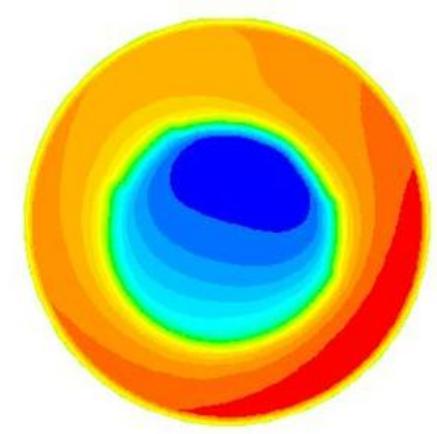

ao high - flow is rotating

Fig. 6: Velocity field at outlet from the model - front face, depending on the centrifugal acceleration

The serial of Fig. 7a to Fig. 7h presents the interfaces of both phases water/air (blue/red) for different inlet water levels (pressures). The water is flowing in from bottom tangential inlet (crosswise to the 
paper plane). For low water levels (a-c), due to low velocity, it falls over and flows directly into the axial outlet - as typical outflow from a vessel. For higher water levels (d-h), the rotating flow in the chamber is creating. All figures are lengthwise vertical cross-sections through the outlet axis.
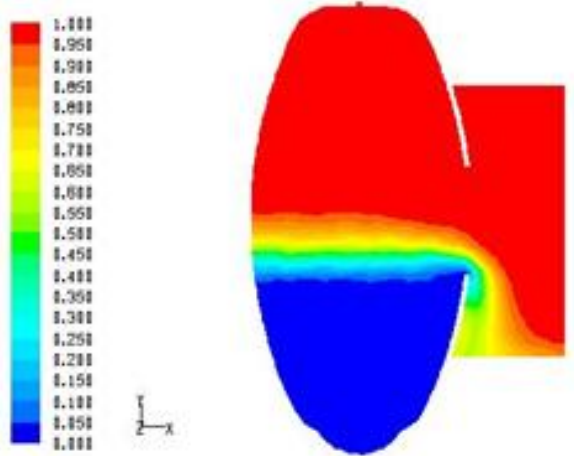

Fig. 7a: At the lowest possible water level the water hardly flows over bottom edge of the outlet directly down on the bottom surface of the flange; the surrounding air is coming in from the right surroundings.

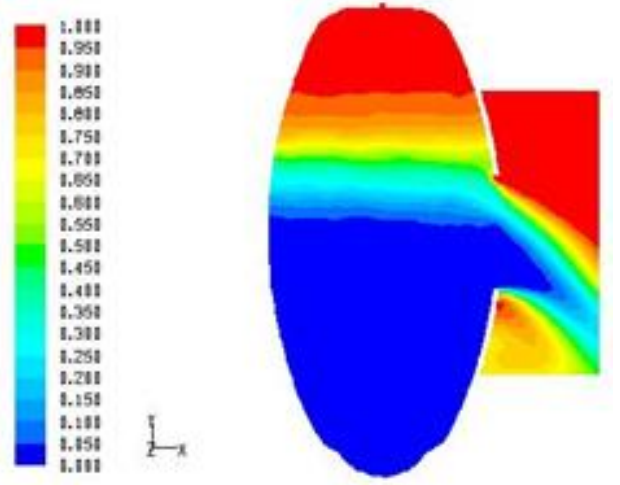

Fig. 7c: Water level defined at the upper edge of the outlet, the flow is separated from the chamber wall, there is visible the beginning rotating flow, the airflow in vent hole practically does not flow out.

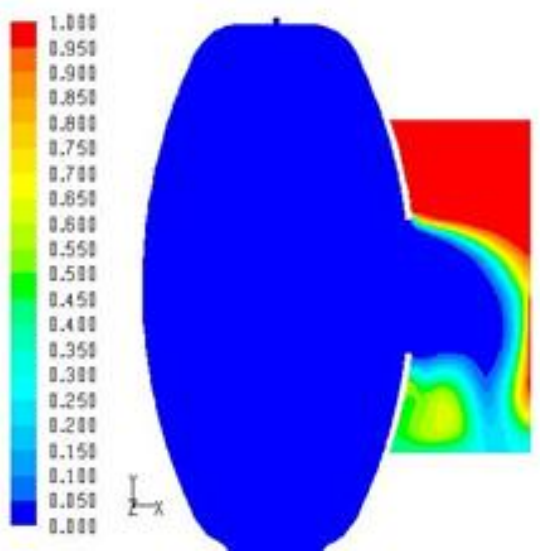

Fig. 7e: Water level just over upper edge of the chamber, the expressive rotating flow inside; outside begins the transformation of gravitational flow into water splashing (spraying).


Fig. 7b: Water level is defined just on the outlet axis, situation is similar, and the outflow is more intensive. The level (theoretically horizontal) is inclined to the outlet.
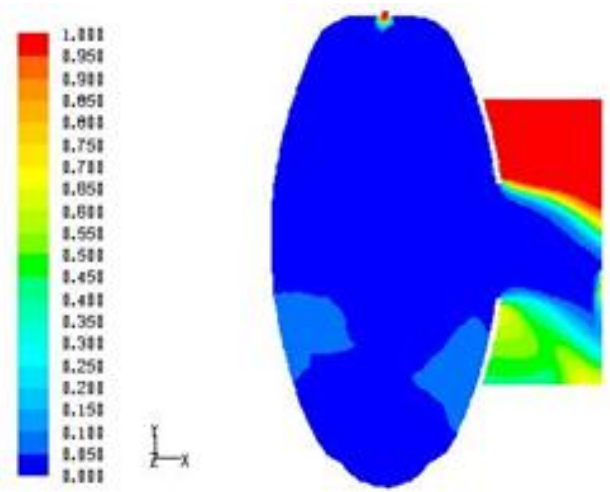

Fig. 7d: Water level just under upper edge of the chamber, the rotating flow inside is transforming into axial outer flow; the gravity influence is visible yet.
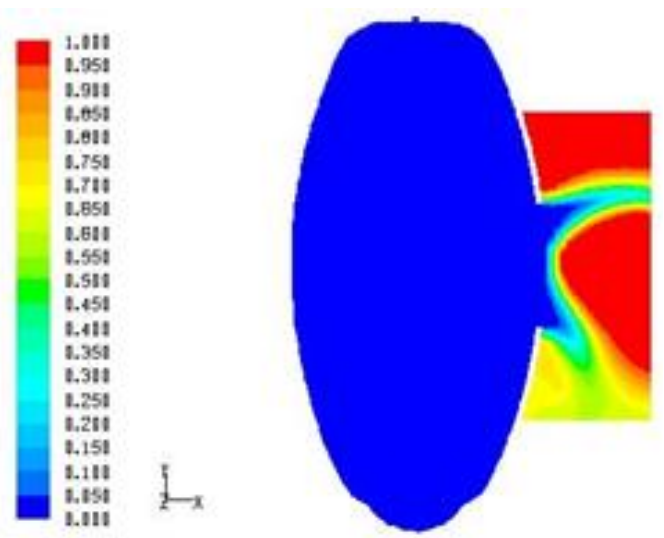

Fig. 7f: The expressive inner rotating flow causes the spraying of the axial water flow into a conical shape, in the middle filled by back flowed air, deformation due to the gravity. 



Fig. 7g: At higher water level, the expressive rotating flow persists. The conical water spray partially hits on the inner wall of the flange and is coming back. The gravity influence is less, but still evident is the some flow along the bottom wall of the flange.
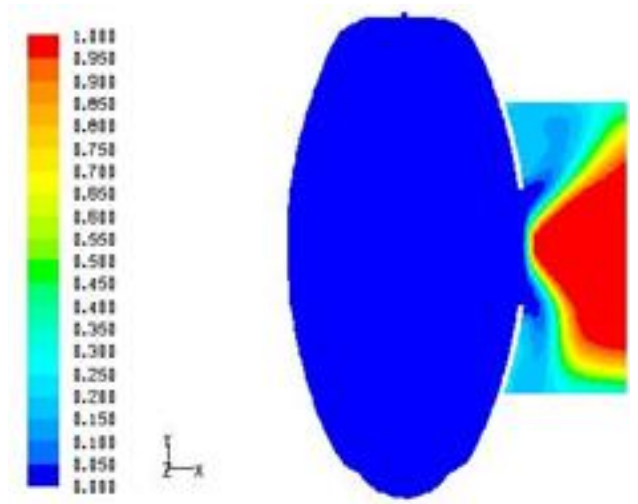

Fig. 7h: Continuation of the previous for the max. defined water level (pressure of $20 \mathrm{kPa}$ ). Higher part of the sprayed flow hits the inner walls of the flange and is rotating there.

\subsection{Resistance characteristic}

For several water levels (hydrostatic pressures) relevant cases were solved, see above Fig. 7. From received results the flow characteristic

$$
V\left[\mathrm{~m}^{3} / \mathrm{s}\right]=f(\Delta p[\mathrm{~Pa}])
$$

was evaluated and after recalculation of volume flow into mass flow

$$
m=V . \rho
$$

the inverse resistance characteristic in the Fig. 8 was evaluated as

$$
\Delta p[P a]=f(m[k g / s]) \text {. }
$$

The characteristic has two parabolic branches of different gradients. The „switching-over“ area is coming when the water level is just around the upper outline of the valve chamber. Flow through the system without rotation (or with partial rotation, only) is passing into the flow of fully created rotating flow. The numerical solution in this „switching-over" area is not stable, the stabilization needs longer calculating time. Probably, the instability is given by alternating airflow in and out through small vent hole in the highest point of the valve body. Such small orifice acts as large flow resistance and the response on the chamber filling is delayed. Maybe, more stable solution could be possible with large vent diameter, finer calculating mesh etc. (not tested). Another influence is the transition into the fully rotating flow. For better description of this area, it should be create more calculations. For the smallest flows, the curve gradient is higher - at the lowest water level the flow width is much less than outlet diameter.

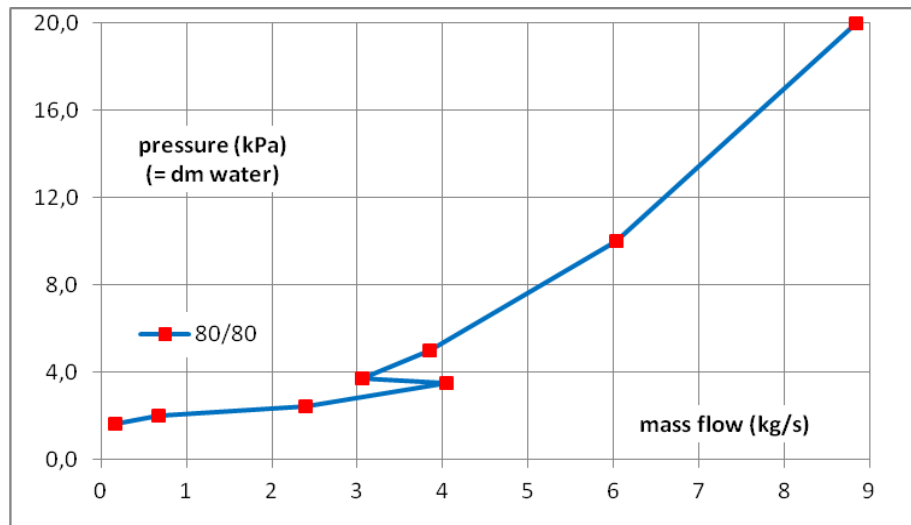

Fig. 8: Resistance characteristic of vortex valve (numerical simulations).

They are visible two different modes of the flow: 
1. Flow with free water level inside the chamber (smaller water level, smaller gradient of characteristic) - water flow, disturbed by tangential inlet, flows out freely from the outlet.

2. Flow without free water level inside the chamber (higher water level, higher characteristic gradient) - water from the tangential inlet is rotating inside the chamber and on the outlet edge, the compact flow is sprayed into individual drops.

\subsection{Flow coefficient}

For free flow, the theoretical outlet velocity is logically higher, comparing with the real flow velocity in a real valve with flow resistances. The comparison of such theoretical value with simulated value is on the Fig. 9.

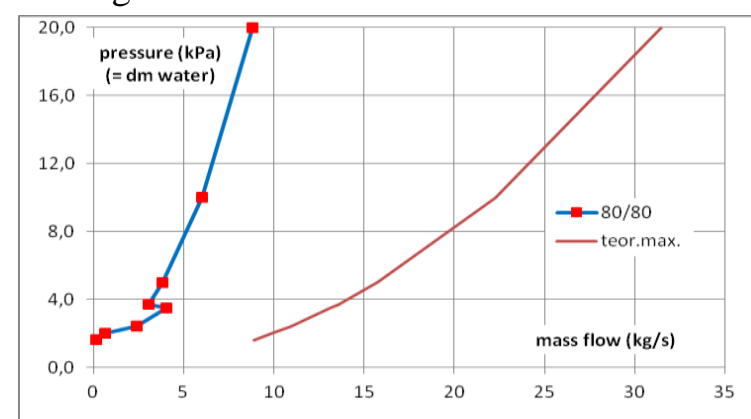

Fig. 9: Real (low) mass flow through simulated valve and ideal (high) mass flow through simple opening.

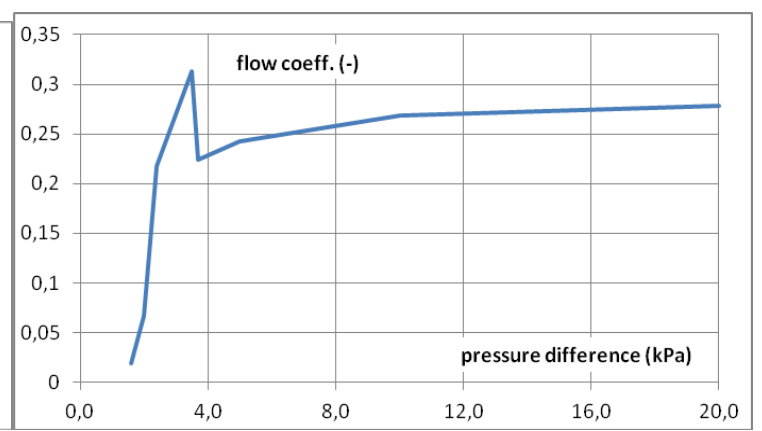

Fig. 10: Flow coefficient for the case from the Fig. 9.

Further, there is derived so-called flow coefficient

$$
\varphi=m_{\text {real }} / m_{\text {id }}
$$

containing all losses of the valve (inlet, friction in inlet tube, inlet in the chamber, rotation and friction in the chamber, passing into the outlet, flow in the outlet, flow separation, all as three-dimensional flow). Received values of flow coefficient for observed case presents the Fig. 10. For high flows, the value is approaching to 0.28 , with decreased flow the value is decreased to the value of 0.2 . For small flows, the maximum value is 0.31 and with flow decreasing, the value is decreasing quickly, first for water level under $0.2 \mathrm{~m}$, where the cross-section of outlet is decreasing in the transverse direction, too. Extrapolating the simulations up to very high value of $200 \mathrm{kPa}$ we can state, that flow coefficient does not exceed the value 0.3 approx.

\subsection{Remark to the effect of the vortex valve}

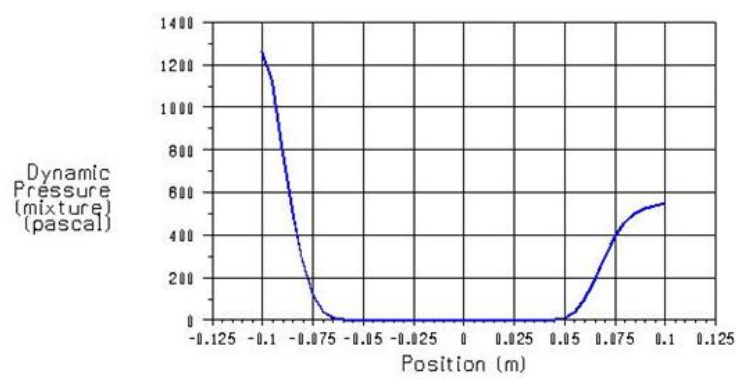

model of vortex valve

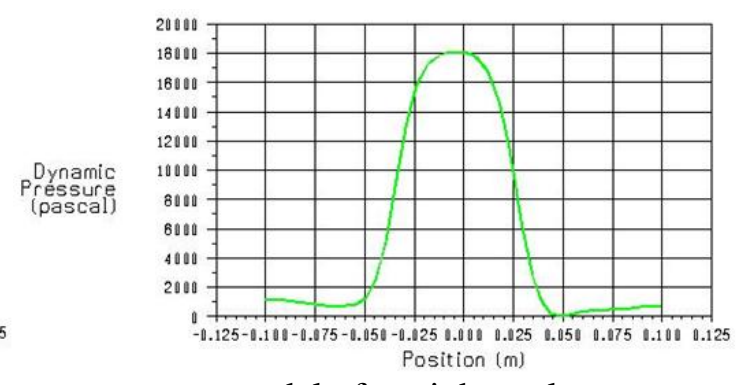

model of straight outlet

Fig. 11: Profile of the dynamic pressure in vertical plane of outlet section

The Fig. 11 left presents the profile of dynamic pressure in vertical cross section through outlet plane for the previous case. In the large central part, the pressure is equal to zero (atmospheric). At the periphery, only, the values of $1.2 \mathrm{kPa}$ (negative $\mathrm{x}$-axis, down, here left) and $0.6 \mathrm{kPa}$ (positive $\mathrm{x}$-axis, up, here right) respectively are reached - due to the gravitation the flow is slightly bent down. Mass flow of $8.8 \mathrm{~kg} / \mathrm{s}$. 
The Fig. 11 right presents for the comparison, only, the similar graph of dynamic pressure for wellknown simple cylindrical outlet. In this model, the outlet dimensions and the pressure difference are the same, but the rotational effect is none. The result is typical for sharp outlet flow - the maximum of $18 \mathrm{kPa}$ at the axis for mass flow of $23.8 \mathrm{~kg} / \mathrm{s}$, i.e. 2.7 times higher, relative to the Fig. 11 left. Decreasing the outlet at $50 \mathrm{~mm}$ approx. the mass flow could be decreased at above-mentioned value of $8.8 \mathrm{~kg} / \mathrm{s}$ and the dynamic pressure could be theoretically $2.5 \mathrm{kPa}$ approx., so still higher, compared with vortex valve on the Fig. 11 left. The value down (here left) is slightly higher then up (here right) again, due to the gravitation effect.

\subsection{Outlet changes}

After detailed analysis above the next similar solutions were made for valves of other outlets. Using suitable outlet inserts for the same valve body, is possible to get the range of flow up to 6.25:1. Similar sets of flow fields as above are not presented here again, due to their large extent. However, results are presented in the summary graph Fig. 15 below. Some few results follow, only.

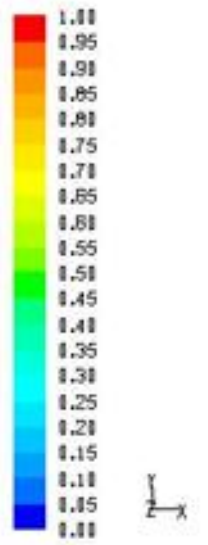

$$
\Delta \mathrm{p}=2 \mathrm{kPa}
$$



$I_{2}$

$$
\Delta \mathrm{p}=20 \mathrm{kPa}
$$

Fig. 12: Phase interfaces in reduced outlet

Reduced outlet is operating as classical nozzle, used as the flow acceleration. The characteristic shape is fluent, at higher water levels the outlet flow remains compact and rotating, with slight bending due to the gravity, but without spraying, see the Fig. 12 for pressure gradients of $2 \mathrm{kPa}$ and $20 \mathrm{kPa}$. Unsuitable strong dynamic effect of the outgoing flow on walls in the surroundings.
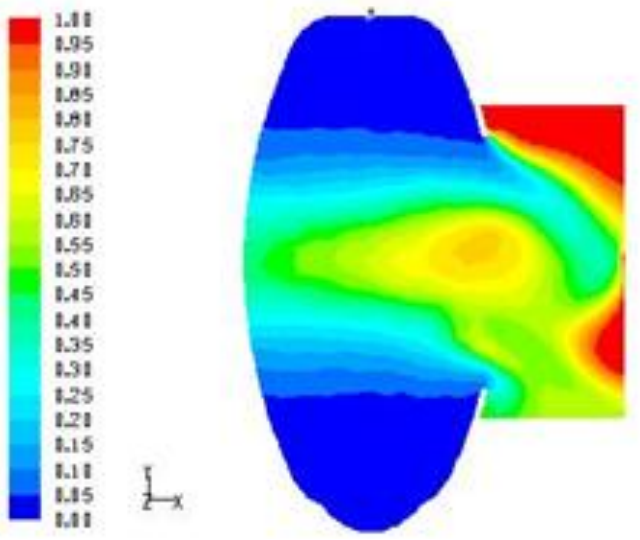

$\Delta \mathrm{p}=2 \mathrm{kPa}$

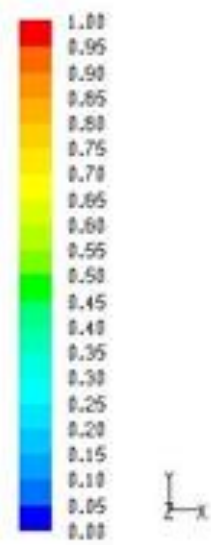

$\Delta \mathrm{p}=20 \mathrm{kPa}$ - error: inverted colour scale!

Fig. 13: Phase interfaces, $2 \mathrm{x}$ enlarged outlet area

Using enlarged outlet cross section, inside the inner volume there is created an expressive rotating water ring. The outside air is coming inside along the rotation axis; the air amount is greater than for original outlet diameter. The Fig. 13 presents the situation for the outlet area 2 times larger in comparison with the basic case from the Par. 2. 
Using 4 times larger outlet cross section, the simulation is unstable for pressure under $3.5 \mathrm{kPa}$, i.e. for water level under upper outline of the chamber. The pressure field is not uniform, too, due to the very large outlet cross-section; the rotating water ring does not create. Along the axis there is visible large area filled by outside air.

\subsection{Outlet edge chamfering}

The velocity fields on the Fig. 14 present that better flow spraying realizes on the thin outlet edge (a), while on the long cylindrical outlet (b) the spraying effect is suppressed. It recommends the chamfering the thick outlet edge of $90^{\circ}$, with enlargement downstream (c).

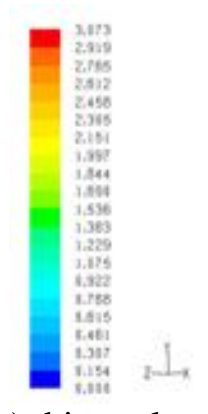

a) thin outlet wall - good spraying

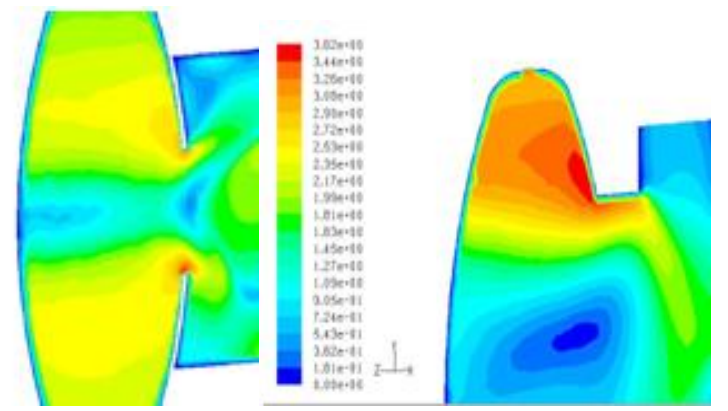

b) thick outlet wall - bad spraying (detail)

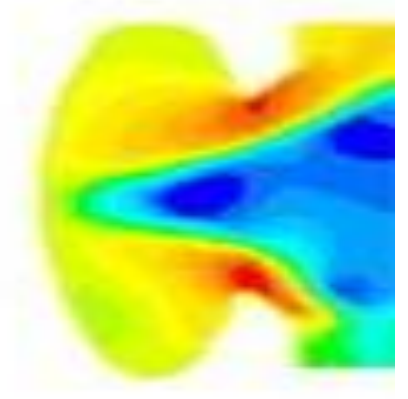

c) chamfered thick outlet wall - good spraying

Fig. 14: Outlet edge influence on the water spraying

Influence of the outlet edge on the spray quality was tested on one case, only. The best solution gives thin and sharp outlet edge, but the long cylindrical extension damps the spraying effect. Some improvement of it gives the chamfered outer edge, where the flow adheres to the chamfering and dissipates in the radial direction. The effect is known from so-called wall nozzles - for suitably designed dimensions the outflow can be bent of over $180^{\circ}[14,15]$ etc.

Generally, the study of spraying quality is not the aim of this paper. The main aim is the suppressing of dynamic effects of outgoing flow.

\subsection{Summary flow characteristics}

The summary of all long-lasting simulations for various combinations inlet/outlet is the sole graph Fig. 15 of resistive characteristics $\Delta p=f(m)$.

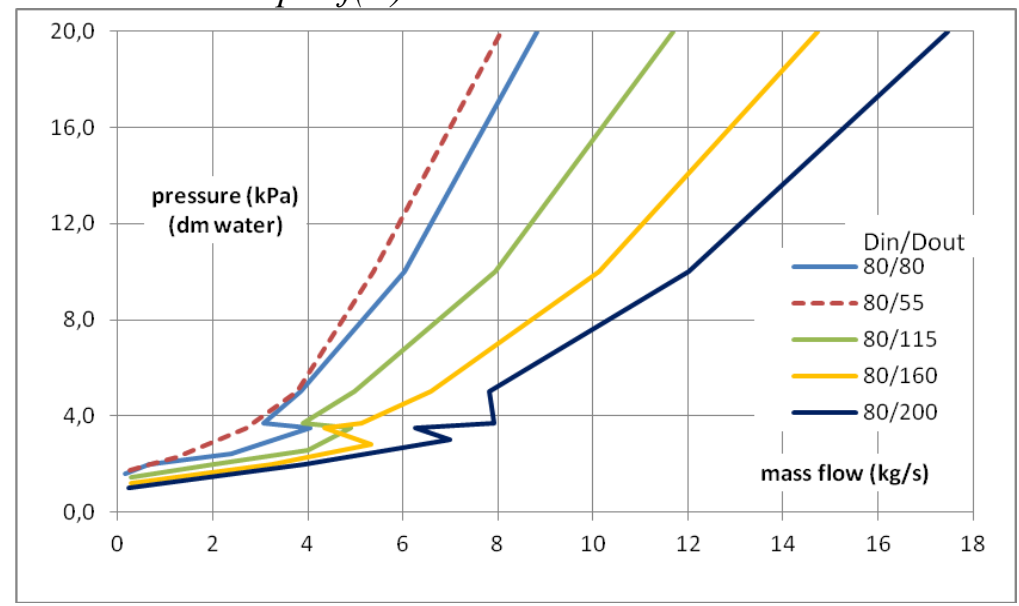

Fig. 15: Summary characteristics for various outlet cross sections, pressure to $20 \mathrm{kPa}$

The valve body geometry and the inlet diameter remain the same; different are the outlet diameters, only, realized as exchangeable inserts. In the unstable transitional area between two branches of each 
characteristic, the numerical errors are higher than in the rest of each characteristic, containing two branches.

\subsection{Testing measurement}

The results of presented numerical flow simulations could be useful for the designing and for subsequent production of vortex valves. Therefore, the results of simulations should be verified by real measurement.

Tested valve was created with one inlet cross section and with several outlet cross sections, realized as exchangeable inserts as 1-2-4 times larger inlet cross sections. The water level was maintained at several certain values, max. $2.0 \mathrm{~m}$. At the outlet water flow there is mounted measuring device.

For simulations were used water levels of $0.5-1.0-2.0 \mathrm{~m}$, for measurement with larger outlets the used pump allows the level 1.6 or $1.2 \mathrm{~m}$, only, so the results of simulations were extrapolated for those levels.

Results of measurements confronted with results of simulations; comparison of both procedures is in the Tab. 1.

Table 1: Simulation compared with measurement (inlet $80 \mathrm{~mm}$ ).

\begin{tabular}{|c|c|c|c|c|}
\hline out/in & level & \multicolumn{2}{|c|}{ flow } & diff. \\
\hline- & $\mathrm{m}$ & \multicolumn{2}{|c|}{ 1/s } & measur.-simul. \\
\hline & & measur. & simul. & $\%$ \\
\hline 1 & 2,0 & 9,2 & 8,8 & $+4,5$ \\
\hline 1 & 1,6 & 7,6 & 8,0 & $-5,0$ \\
\hline 2 & 1,6 & 10,6 & 10,6 & 0,0 \\
\hline 4 & 1,2 & 12,0 & 11,55 & $+3,9$ \\
\hline
\end{tabular}

The coincidence of both procedures is very good; the error does not exceed the error of standard operating measuring devices $( \pm 4 \%)$. Found differences can be caused by several influences:

- The water level before the valve inlet was not constant, as well as the water level after the outlet, where the flow meter was installed.

- Next error is given by definition of zero pressure, i.e. of inlet water level - constant for simulation, slightly uneven for real measuring.

- Some error brings in the used method of numerical simulation, for instance the coarse mesh elements.

Following such positive comparison, it is possible to suppose that the application of numerical flow simulation in vortex valve is the suitable method for determining of valve main dimensions, operating at defined flow. Further, it can be supposed that for geometrically similar shapes of valves their operational characteristics are similar, too.

\section{HIGHER FLOWS}

The basic model in the Par. 3 above solves the operating conditions in the range $0-20 \mathrm{kPa}$ and 8-18 $\mathrm{kg} / \mathrm{s}$ [6]. The next task is to check the suitability of the procedure above for similar pressure gradients of $16-20 \mathrm{kPa}$, but for higher flows of 22-125 kg/s [7].

The preliminary design is realized as enlargement of cross sections from verified solution above, proportional to the higher mass flow. This hypothesis should be verified on specific design using the assortment of semi-finished products [10-13]. Due to the unified design, it should be suitable to use the same valve body and the mass flow to adjust by replaceable outlet inserts, as used in the Par. 3.7 above.

As found above, the branch of higher gradient is valid when the valve body is full by water, and the transition between branches arrives when the water level is on the upper outline of the valve body, approx. For lower water levels, the valve body is not full by water and the inner rotation of water does 
not arises - it exists a free water level, only, waved by the tangential inlet from below and water is then flowing out through the axial outlet.

It is possible to await that in larger valve body the characteristic transition begins for higher pressure difference (water level) than above. However, if used pressure gradient remains the same and valve body diameter is higher, due to higher mass flow, it is possible to await that the real valve operation could be in the unstable region. In addition, it is necessary to check the global adequacy of new dimensions.

Note: The aim of this vortex valve solution in not any perfect spraying of outflowing liquid, as for instance in the spraying gun, but the only decreasing of the dynamic effect of the outflowing liquid on surroundings. It is reached for smaller gradients without sprayed outflow, too, with free water level inside the valve body. A part of the flow energy is changed into flow losses inside the valve body (inlet, friction in the inlet tube and during the rotation, the change of the flow direction from peripheral into the axial, flow spraying, back flow of the air from the surrounding etc.).

\subsection{Trial prismatic model}

For a valve of high volume flow, larger inlet and outlet diameters should be designed together with larger valve body diameter, too. However, by this way the valve body radius $r o$ is increasing and so the centrifugal acceleration $a o=w o^{2} / r$ is decreasing. In addition, lower water inlet level means lower velocity, therefore lower centrigugal acceleration, too.

It is known that this problem is solved by high number of small centrifuges of small outside diameter, where the high value of centrifugal acceleration is reached reliably and simply, for instance at uranium enrichment. Here is alternatively designed simple prismatic shape of the valve body, where the smaller valve radius ro ensures quite high peripheral velocity and centrifugal acceleration, too, and the necessary flow cross section is designed as prolongation of valve body in the axial direction, depending on the necessary flow volume (see below).

Used methods of flow numerical simulation are the same as used and verified in the Par. 3 above, therefore without next details. Results of this trial valve are added as an illustration, only. Contrary to other solved cases, the outlet axis is vertical up, therefore not influenced by the gravity in the direction crosswise to the outlet direction. Similar solution $[3,4]$ uses the outlet axis vertical down.

With increasing of the mass flow, the valve dimensions must be increased, too (body, inlet, and outlet diameters). With increasing body radius ro the centrifugal acceleration, necessary for a good water spraying, is decreasing with the second power of body radius $r o$ as $a o=w o^{2} / r o$. Therefore the vaulted bodies using semi-finished products [10-13] are not suitable, because their outlines are too large, together with dimensions of the built-up area. Better solution is prismatic valve body, where the inlet size is simply increased by the body width increasing (by the cylinder height). At suitable body diameter, the velocity and flow along the periphery do not decrease under suitable limits. For given pressure gradient of $16 \mathrm{kPa}$ the theoretical velocity is

$$
\text { wid }=\sqrt{ }(2 . g . H)=\sqrt{ }(2.9 .81 .1 .6)=5.6 \mathrm{~m} / \mathrm{s}
$$

and the theoretic flow of $143.43 \mathrm{~kg} / \mathrm{s}$ through the prismatic inlet of $0.16 \times 0.16 \mathrm{~m}$. The simulated inlet flow is $61.82 \mathrm{~kg} / \mathrm{s}$, only, so the flow coefficient is 0.43 (the ratio of real - here simulated - flow to the ideal one). Next result of the simulation are the air suction of $1.02 \mathrm{~kg} / \mathrm{s}$ through the front face of surroundings and the outlet flow of $62.77 \mathrm{~kg} / \mathrm{s}$ through the cylindrical periphery of surroundings. The error of the mass balance is $0.07 \mathrm{~kg} / \mathrm{s}$, i.e. $0.1 \%$ of the inlet flow. It is negligible; therefore, the simulation was finished and evaluated.

For presentation of complicated flow field, three cross sections are used, perpendicular to the $\mathrm{x} / \mathrm{z} / \mathrm{y}$ axis. The serial of Fig. 16a to Fig. 16h presents several images of flow field parameters, their short description follows. For better resolution, different scales are used for the same parameter in different cross sections.

Remark: To reduce areas of necessary numerous flow fields, the results are presented in flat orientation - gravitation to the left, along the axis $(+\mathrm{z})$, axial outlet up, along the axis $(+\mathrm{y})$. 

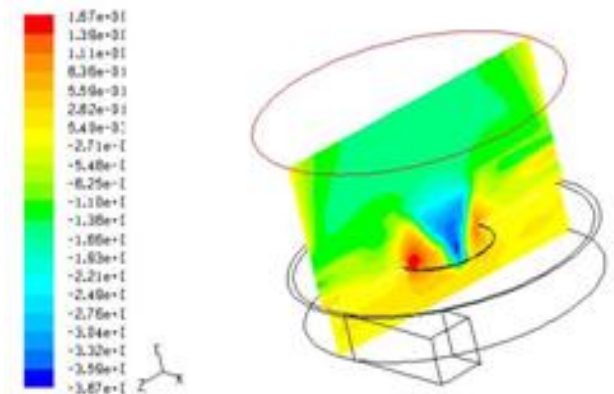

Fig. 16a: Axial velocity (outflow up along the orifice outline, suction down along axis)
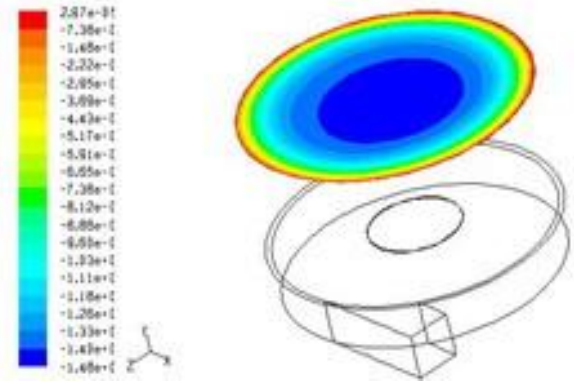

Fig. 16b : Axial velocity at outlet cross section

Axial component of velocity (Fig. 16a, 16b) - the highest value at outlet edges, the highest suction inside along the outlet axis. In the area opposite to the tangential inlet, the flow is higher than at the opposite side. At the outlet, the backflow is visible along the axis.
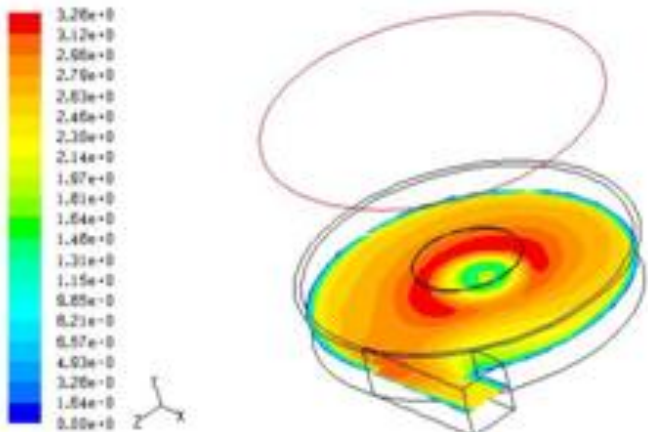

Fig. 16c : Velocity at inlet plane
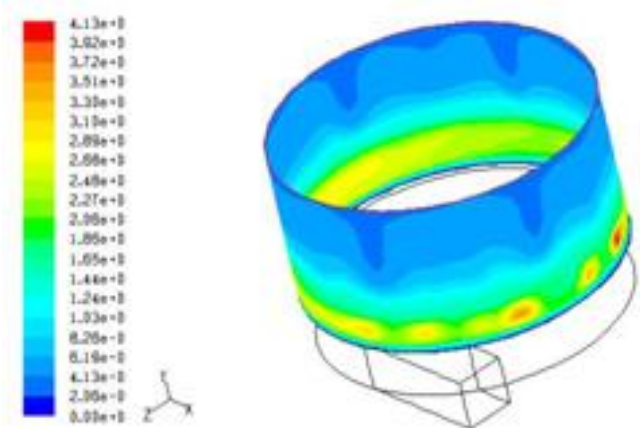

Fig. 16d : Velocity at the outflow periphery

The absolute value of the velocity vector in the cross section through the inlet axis is presented (Fig. $16 \mathrm{c})$. Here is approximately evaluated the peripheral velocity of the rotating liquid body as $2.5 \mathrm{~m} / \mathrm{s}$ at the radius of $0.4 \mathrm{~m}$. In this estimation it should to expect some error - it is hardly to estimate, what part of the liquid body to use for the determination of average peripheral velocity and what is the average radius of such body. From there the centrifugal acceleration is $15.63 \mathrm{~m} / \mathrm{s}^{2}$. Due to the inaccuracy at determination of peripheral velocity and flow radius and also that the gravity affects here in across direction, it should be supposed that a perfect spraying of the flow will not create, rather the flow will spilled out along the whole outlet periphery with some irregularity, due to the onesided inlet.

At the periphery of the outer area (surroundings, Fig. 16d) there is observable some flow thickness, who is flowing on the body surface out in the direction across to the axis, the most intensive flow is opposite to the inlet. Along the periphery are visible some irregularities, feeble points etc. It could be the error of the simulation due to the coarse mesh or little area of surroundings - so that to get shorter time of solution for many solved cases. Similarly at upper edge are some irregularities, but very small, here is hardly any flow.
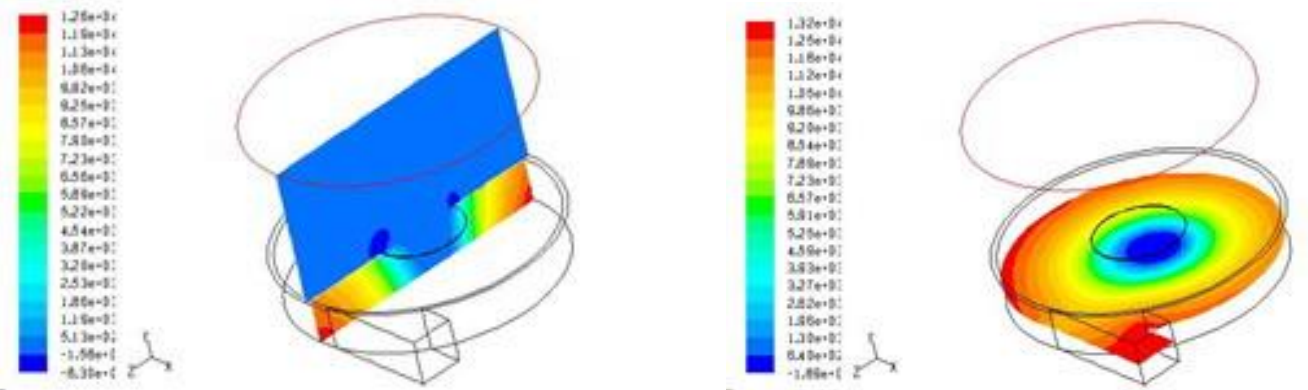

Fig. $16 \mathrm{e}+16 \mathrm{f}$ : Pressure - inversed to the velocity (max. in the inlet, min. in the outlet)

Pressure (Fig. 16e+16f) is inverse to the velocity, maximum at the periphery of valve body, is decreasing to the axial outlet, where is going under atmospheric pressure of surroundings. 

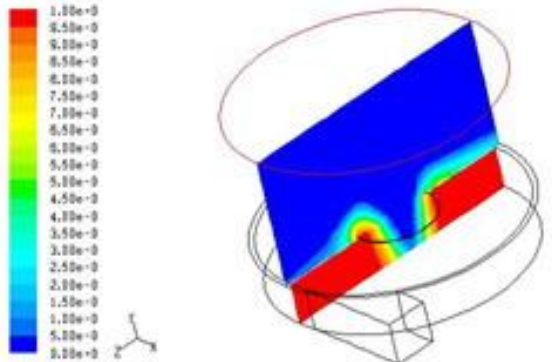

Fig. 16g : Water phase (red, max. inside)
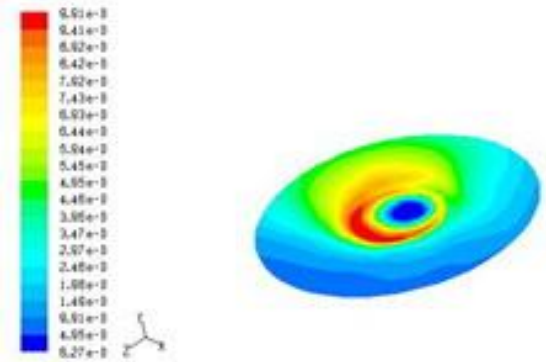

Fig. 16h : Water phase - outlet plane - asym. spraying The field of water part (phase 1) presents the water spillage on the body surface after the outflow (Fig. $16 \mathrm{~g}+16 \mathrm{~h}$ ). The outflow is not symmetrical, facing to the tangential inlet there is higher peripheral outlet. The same is visible in the cross section in the outlet plane, too. Remark: Similar case see [4] uses vertical outlet down, when the outer surface of the valve remains dry, but the overall height of the structure is higher.

\subsection{Modelled cases}

The previous serial of Fig. 16 shows that the detailed presentation of all necessary flow field parameters is very extensive, therefore below are presented directional fields, only, at the outlet from cylindrical surroundings - through both front and peripheral surfaces. They indicate the quality of sprayed flow in solved models 1-4.

Model $1(21.3 \mathrm{kPa}, 30 \mathrm{~kg} / \mathrm{s})$

Hydrostatic pressure is quite high; therefore, the spraying is very good. In the smaller valve body and at the higher pressure gradient the image of the outlet flow field is very good; see the Fig. 17, the deviation of individual vectors from the radial direction is the consequence of the tangential inlet, followed by flow rotation. Spraying is uniform, slightly more down - consequence of gravity.

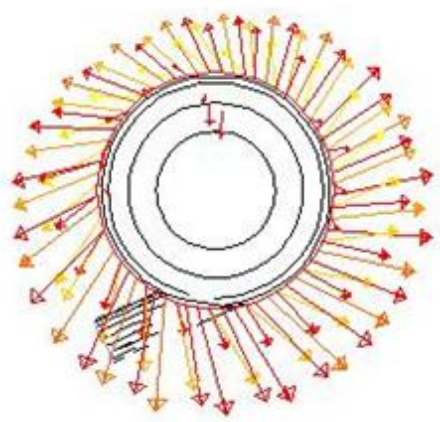

Fig. 17a: Phase 1 - water is going out through the periphery, only, not through the face

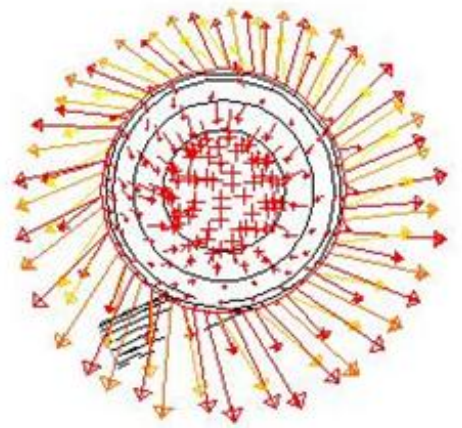

Fig. 17b: Phase 2 - air is drawn in through the axial face, going out through the periphery, together with water

\section{Model $2(15.9 \mathrm{kPa}, 105 \mathrm{~kg} / \mathrm{s})$}

Large prismatic arrangement with lower hydrostatic pressure (80\% only) and 7 times higher water flow, compared with the case in the Par. 3.1. The result is partial spraying, only, through the upper part of the periphery and air suction through both the axial middle part and lower part of the periphery, see the Fig. 18. 


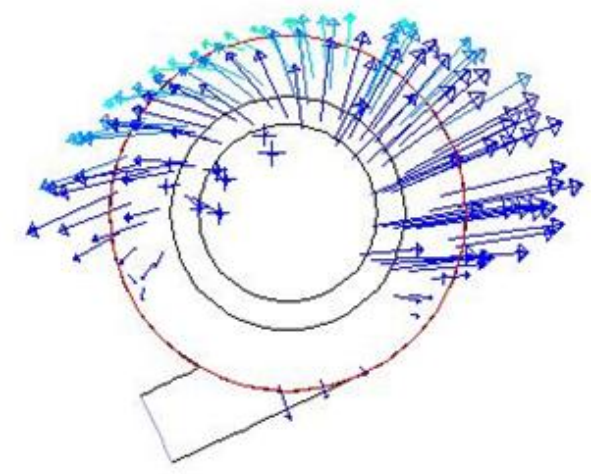

Fig. 18a: Phase 1 - water is flowing through the upper part of the periphery, it is visible small backflow.

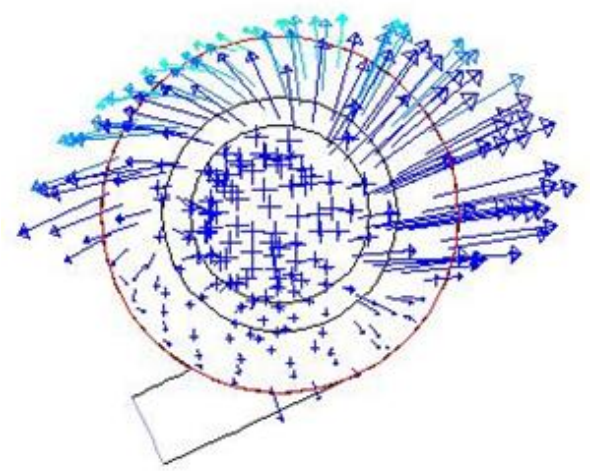

Fig. 18b: Phase 2 - air is drawn inside through both middle axial part and lower part of the periphery, going out together with water through the upper part of the periphery.

\section{Model $3(16.3 \mathrm{kPa}, 22 \mathrm{~kg} / \mathrm{s})$}

Given operating point is similar to the model 1, but after the directional field on the Fig. 19 the spraying is bad, the water is flowing across the outlet face down, in the gravity direction. Maybe the consequence of lower water level ( $75 \%$ of the case 1 , only).

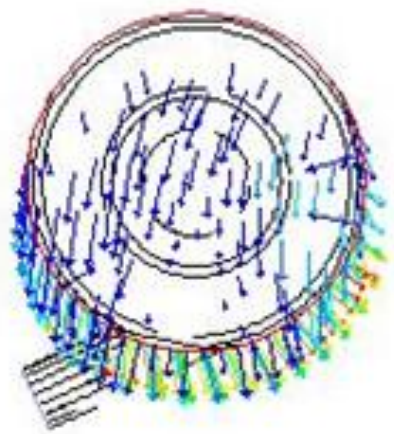

Fig. 19a: Phase 1 - water is flowing out through the lower part of the periphery, but through the front face is flowing down, only.

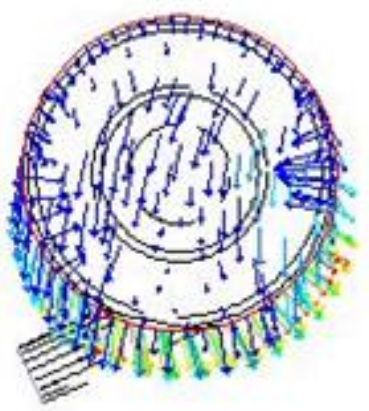

Fig. 19b: Phase 2 - air suction slightly from the upper side and intensively in the horizontal plane, the outlet down together with water.

The only remedy is the decreasing of the valve body diameter with original sizes of the other parts. By this, the velocity is increasing and the spraying will be better. Next decreasing of the outer diameter is not possible due to the "short-circuit" flow from inlet into outlet, without flow rotation inside. Directional field of such modified case see the Fig. 20.

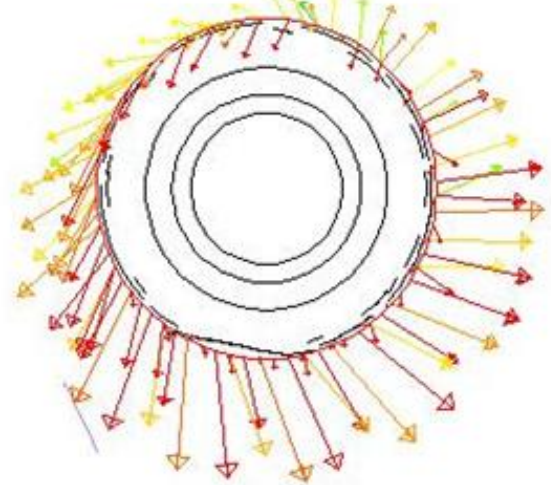

Fig. 20a: Directional field in the cylindrical

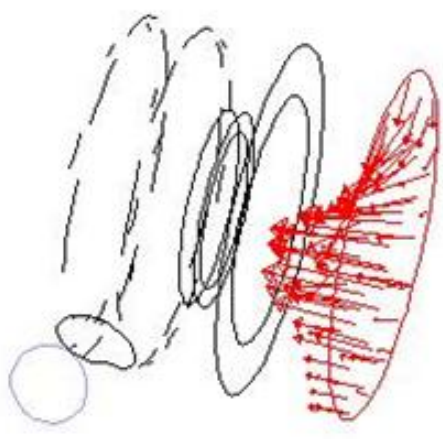

Fig. 20b: Directional field on the front face of 
outlet surroundings is quite uniform, but outlet in the upper part is feeble. cylindrical outlet - suction is slightly asymmetric.

Some next details of the flow field in modified model 3 see the Fig. 21.

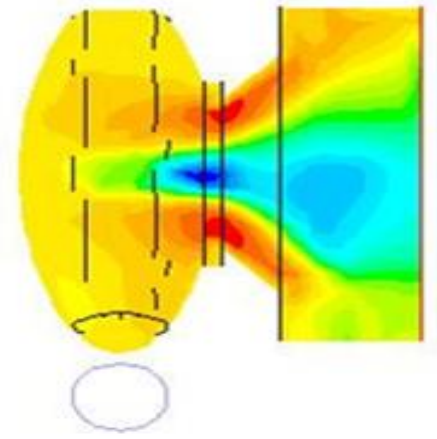

Fig. 21a: Field of axial component of velocity in lengthwise vertical cross-section - spraying through the periphery, suction through axis. Good result.

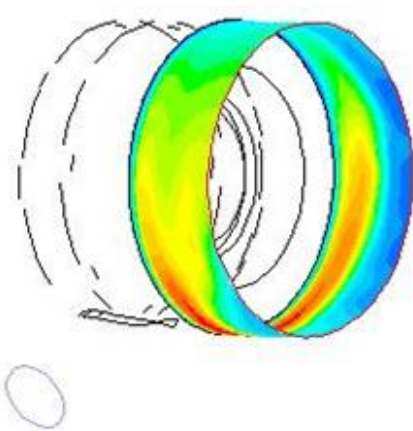

Fig. 21b: Velocity field at the outlet periphery - intensive outflow is close to the outlet orifice, more down than up influence of gravity.

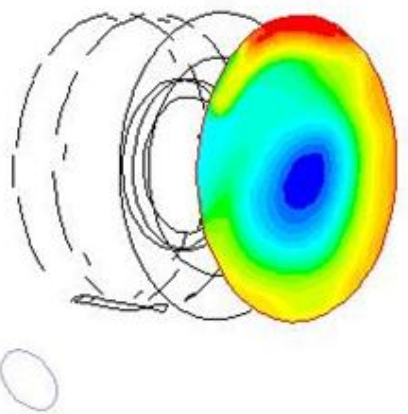

Fig. 21c: Field of axial velocity at the front face of surroundings - outflow through the periphery, suction through the axis, in general slightly asymmetric (influence of tangential inlet).

Model $4(15.8 \mathrm{kPa}, 125 \mathrm{~kg} / \mathrm{s})$

The biggest model of prismatic inlet 160x320 mm. Mass flows after simulation $129.8 \mathrm{~kg} / \mathrm{s}$ at the inlet, outflow $8.2 \mathrm{~kg} / \mathrm{s}$ through front face and $121.6 \mathrm{~kg} / \mathrm{s}$ through the periphery, error of mass balance 0.04 $\mathrm{kg} / \mathrm{s}(0.03 \%)$ can be neglected. The inlet flow corresponds to the task, for its exact setting it should be made next iterative calculations. For checking of spraying quality see the directional field on the Fig. 22. This result was used for the model 2 , too, its lower flow is reached by proportionally lower outlet.

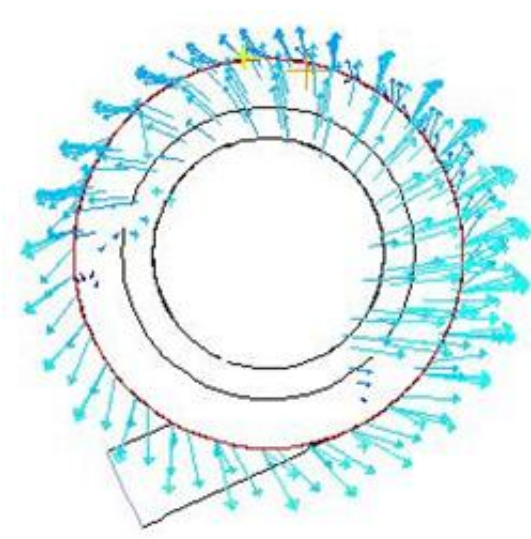

Fig. 22a: Phase $1-$ water is going out through the periphery, quite uniform, a little more down (gravity).

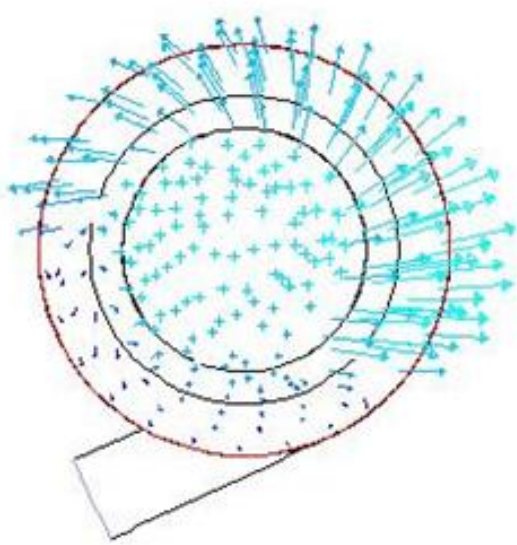

Fig. 22b: Phase 2 - air - suction in along the axis, outflow through the upper part of periphery together with water.

\section{Supplement - spiral case of flat valve}

Model 4 above was modified by spiral outer case. Made as qualitative comparison, only, the spiral shape is designed without detailed calculations. Singular point at the tangential transition from inlet tube into valve body is removed, to prevent possible complications during meshing. 


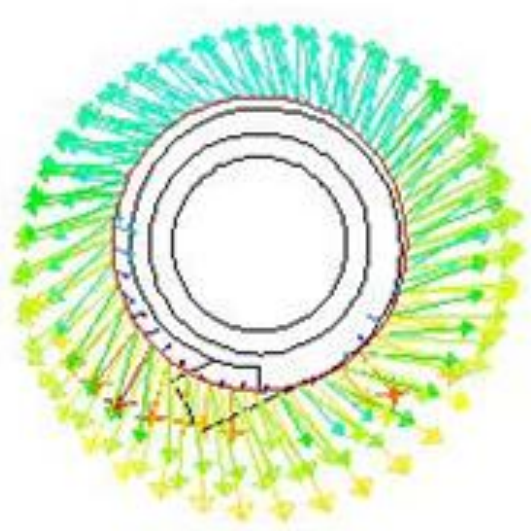

Fig. 23a: Spiral case - uniform water outlet through the entire cylindrical surface, due to the gravity a little more down.

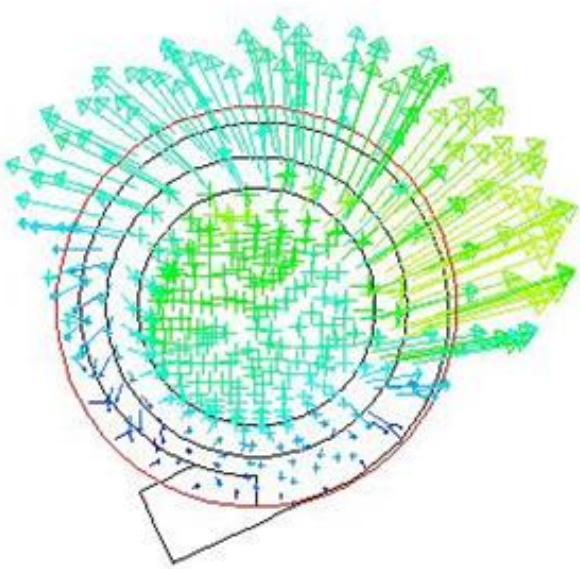

Fig. 23b: Spiral case - air back suction from the surroundings along body axis and through the lower side, outlet through the front face in the upper side.

Comparing Fig. 22 and Fig. 23, it is possible to state that the resulting directional field of spiral valve body is similar to the cylindrical one. It is interesting that the flow is increased of $20 \%$ approx., at the same boundary conditions. It means that the resistance of such valve of spiral case is lower, which is not good for intended purpose - to suppress dynamic effect of the outflow on the surrounding.

\subsection{Flow coefficient}

So-called flow coefficient of individual cases presents a check value and an information about the flow quality. It is defined as the rate of real (here simulated) flow and of idealized one. As an information, the coefficient for so-called quarter circle nozzle reaches of 0.95-0.97, for simple drilled hole in the wall of 0.64 , for smaller vortex valves solved above in the Par. 3.3 of 0.28 , only. Here solved smaller and vaulted cases $1+3$ have the coefficient of $0.50-0.58$, larger and flat cases $2+4$ of 0.37-0.45. The influence of vaulted shape on the flow quality is higher here, the influence of lower resistances in larger dimensions is not so important here.

\subsection{Summary flow characteristics}

Inlet data for valve designer are not only the main dimensions, but also the so-called operational (resistance) characteristic $\Delta p=f(m)$, too, well known as quadratic function, see the Fig. 15 above for small flows. The Fig. 24 presents results of the Par. 3 (Fig. 15), together with results of the Par. 4. Here are solved higher flows, only, just before the overflow over the security overfall. So the lower branch of the characteristic is not solved here. 


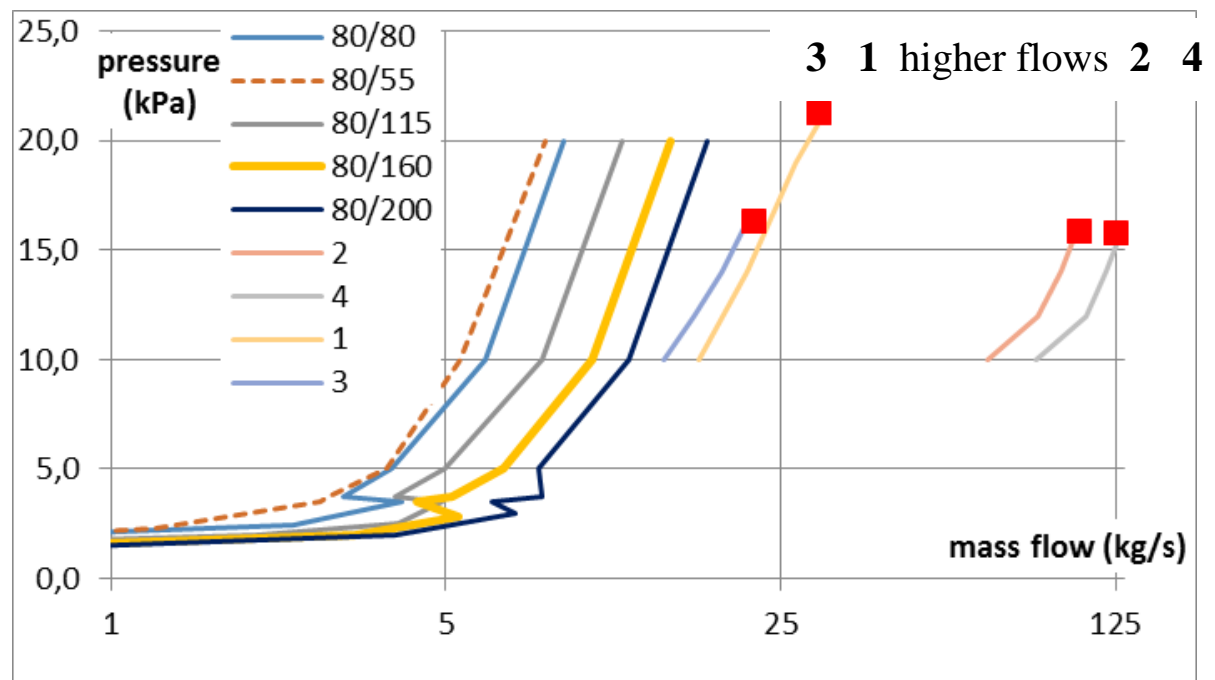

Fig. 24: Operational (resistance) characteristics for low flows (cases 80/xx) and high flows (1-4)

For the valve body diameter of $780 \mathrm{~mm}$ (cases $2+4)$, it is possible to estimate that the transition between lower and upper branch of characteristic is of $10 \mathrm{kPa}$ approx. Therefore simulations were made for the range of 10-12-14-16 kPa, the same for valves of medium sizes (cases $1+3$ ), where the transition area could be estimated lower, maybe 5-7 kPa. Four solved points of each characteristic are the minimum for quadratic functions.

As found out in the Par. 3, the branch of the characteristic with higher gradient begins when the valve body is full of water. For here solved higher flows, i.e. larger valve bodies at the same maximum water level it could mean the operation in transitional area between both branches. Therefore, the spraying quality could not be good, but our main task is to suppress the dynamic effect of the flow, not the spraying quality.

All characteristics for higher flows, as result of many simulated cases, are presented in the common graph Fig. 24, together with characteristics of small valves (Par. 3). Due to large extent of flows, the scale of the $\mathrm{x}$-axis is logarithmic. The graph confirms the preliminary estimations that the used lower point of the characteristic of $10 \mathrm{kPa}$ is far from the transitional area for cases $1+3$ (middle flows, middle valve sizes), but for cases 2+4 (large dimensions, large flows) the lower parts of their characteristics are bent, what signs the vicinity of the transitional area.

Note: For cases of small flows in the Par. 3, the transitional area is at the level of 3-4 kPa, only.

The last Fig. 25 presents possible operating range of one size of valve body $(\phi 450 \mathrm{~mm})$ and valve inlet $(\phi 100 \mathrm{~mm})$ and for several simply replaceable outlet inserts $(\phi 100-\phi 250 \mathrm{~mm})$ for pressure range of $5-20 \mathrm{kPa}$ (water levels of $0.5-2.0 \mathrm{~m})$. For lower outlets $(\phi 100+\phi 145 \mathrm{~mm})$ is visible the typical quadratic shape of the characteristic, but for larger outlets $(\phi 200+\phi 250 \mathrm{~mm})$ is clear that the flow at minimum pressure of $5 \mathrm{kPa}$ belongs probably to the lower branch of the characteristic (it should be make more simulations in this range). 


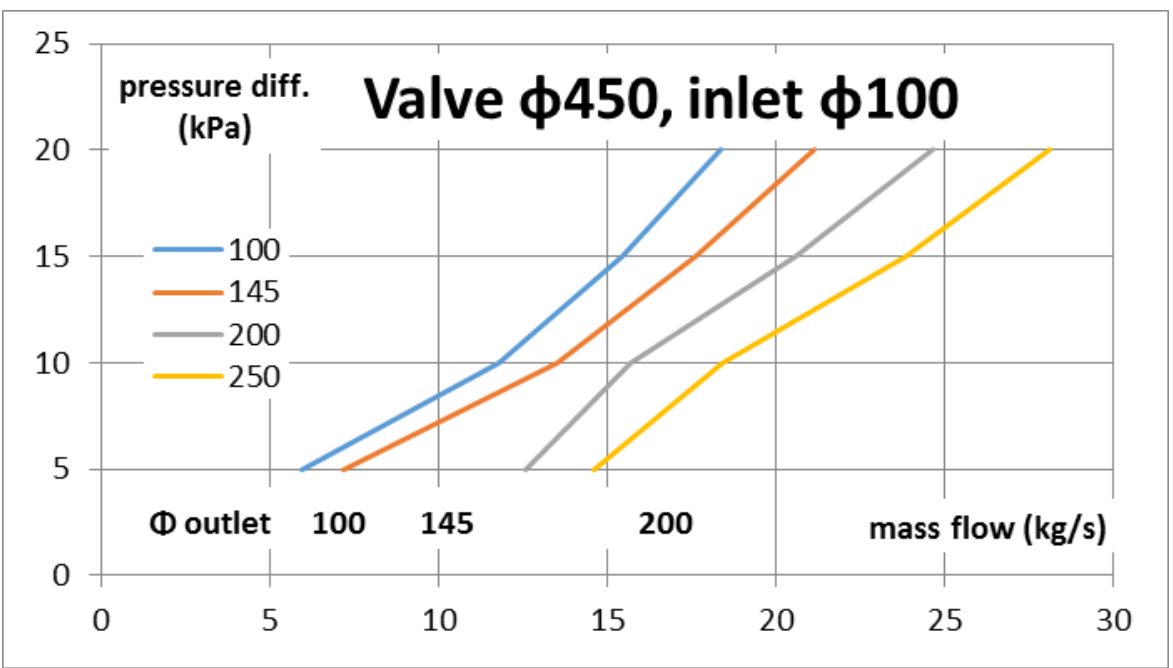

Fig. 25 : Operational field of one size of valve body with replaceable outlet inserts.

\subsection{Design}

For each of 4 solved cases of higher flow and lower pressures the suitable main geometric parameters of valve (outlines, inlet and outlet diameters) were found to get given water flow for given pressure gradient (i.e. hydrostatic pressure of given water level).

Initial dimensions of new cases were derived from former solved and verified cases in the Par. 3, using simply the continuity equation. The flow change by cross section change is the initial inlet parameter, only. However, flow resistances during the complicated 3D flow (inlet, rotation, interaction of rotating and entering flow, transition from rotation into axial outlet, spraying, friction etc.) have important influence. For such case, it is not possible to apply simple one-dimensional equations from basic course of fluid mechanics, but tree-dimensional numerical flow simulation is necessary.

Each modelled solution should be verified by experiment - any model is some approximation of the reality, only, it is necessary to check, if a simplification does not change the results too much.

Presented result of each solved implicit case is reached in several iterative steps.

From the convergence course of the solution it is possible to estimate, that some cases with oscillating convergence could be unstable in real operation, i.e. with irregular spraying, pulsating flow, higher noise level etc. Typical for transitional area between two branches of characteristic.

The main aim of the solution is not the quality of the spraying at the outlet, but reduction of dynamic effects of the outgoing flow, therefore next simulations were not realized. In given cases the water level is relative low, so at relative large inlet and outlet does not expect uniform spraying along the whole outlet periphery.

The initial design uses vaulted shape of the valve body, for higher flows is used flat design, where the cross section is changed by the valve body width along the axis, the diameter must kept lower, to reach suitably high value of centrifugal acceleration.

In smaller valve body (cases $1+3$ ), the peripheral velocity is higher, so the spraying is better, too. However, the inlet diameter must pass between outlines of valve body and valve outlet, to prevent ,short-circuit“ flow between inlet and outlet without flow rotation inside.

Both inlet and outlet diameters define approximately the possible flow range. If the outlet is smaller than inlet, the outlet flow tends to be straight and strong without spraying. If the outlet is equal or larger than inlet, the water spraying will be good. 


\section{CONCLUSION}

To cover variable hydrostatic pressures and volume flows, the valve design uses the range of prefabricated parts. For higher flows and lower hydrostatic pressures the valve body diameter should not exceed suitable value, to preserve sufficient peripheral velocity, necessary for water spraying. In such a case, the necessary flow cross section is realized by body prolongation in axial direction.

For determination of branched resistance characteristic $\Delta p=f(m)$ resp. $\Delta p=f(V)$ for observed models it should be to test at first a suitable procedures of the solution. Because of very high number of necessary simulations, the procedure should be the shortest, but with warranted and verified results. Therefore, the shorter but not so exact steady method "mixture" is used, not the unsteady long-time but more precise method "VOF".

Prepared method was used for shape variations of basic model; from many received results, the summary characteristics are evaluated: The final simple graphs can be used for prediction of new model series of valves.

At the end, it should be noted that any simulating model is a better or worse approach to the reality, only, which should be tested by measuring on real piece and so make sure that results of simulation are in the conformity, either very good, or acceptable, or approximate only. In cases presented above, the coincidence between simulation and reality is very good.

\section{Acknowledgement}

Our acknowledgment is given to VUTS Liberec - Center for Development in Machinery Research for the support in the framework of the grant NPU-LO1213, granted by the Czech Ministry of education, youth and sport.

\section{References}

[1] Jarman, D., Butler, D., Tabor, G., Andoh, R.: Modelling of vortex flow control at high drainage flow rates, ICE proceedings - Engineering and computational mechanics, Vol. 168 issue EM1

[2] Andoh, R.Y.G., Faram, M.G., Osey, K.: Vortex flow controls in integrated storm water management for urban environments, Proc. of the 6th int. water sensitive urban design conference and hydropolis, Perth Australia, 2009

[3] Steinriede, H., Merschdorf, M.: Wirbeldrossel - product information, UFT 2016

[4] Brombach, H., Steinriede, H.: Vertical vortex valve - product information, UFT 2014

[5] Tesař, V.: Superquadratic fluidic restrictors and their applications, Advances in fluid mechanics IX, WIT Transactions on Engineering Sciences, Vol 74, 2012

[6] Adámek, K., Koláŕ, J., Peukert, P.: Vortex valve, Proc. of the Int. Conf. EFM, p. 15-22, Mikulov, 2017

[7] Adámek, K., Kolář, J., Peukert, P.: Vortex valve used as controlled outflow of storm water, Proc.of the int. conf. AEMFME, Rajecké Teplice, 2018

[8] Software Fluent, actual version

[9] Vortex valve, patent US 3219048 from 23.11.1965

[10] Catalogue of valves producer www.bmto.cz

[11] Catalogue of semi-finished parts www.zyksal.cz

[12] DIN 28011 - Vaulted foreheads, stainless steel

[13] DIN 17458 - Tubes seamless, stainless steel

[14] Coanda, H.: US Patent No. 2,052,869. Device for Deflecting a Stream of Elastic Fluid Projected into an Elastic Fluid (1936).

[15] Adámek, K. et al.: Wall flows and their applications, in: Int. Journal of Mechanical Engineering and Applications, special issue Numerical flow simulations in textile technology, 2015, 3(2), p. 28-32 